\title{
Criopreservação de medula óssea e células pluripotentes periféricas utilizando um congelador programável: experiência em 86 congelamentos
}

\author{
C.M. Massumoto, S. Mizukami, M.F. Campos, L.A.G. SIlva, A. Mendrone J R., A. Sakashita, E. Zambon, \\ M. Ostronoff, M.C. A. Macedo, R. Medeiros, P. Dorlhiac, D. Chamone, F. Dulley \\ Disciplina de Hematologia e Hemoterapia da Faculdade de Medicina da Universidade de São Paulo. Departamento de Transplante de \\ Medula Óssea da Fundação Pró-Sangue/Hemocentro de São Paulo, São Paulo, SP.
}

RESUMO - A infusão de células hematopoéticas totipotentes criopreservadas permite a recuperação da hematopoese após quimioterapia mieloablativa.

Овј етіvo. A formação de cristais de gelo durante o processo de congelamento é o fator principal que causa ruptura das estruturas celulares. A criopreservação dessas células a uma taxa constante preveniria os danos causados pelo congelamento brusco.

Métodos. Vinte e três pacientes com mediana de 25 anos (variação 3-57) tiveram a medula óssea e/ ou células-tronco periféricas (CTP) coletadas no período de março de 1993 a outubro de 1994, totalizando 86 congelamentos. Os pacientes apresentavam as seguintes neoplasias: linfoma nãoHodgkin $(n=5)$, leucemia mielóide aguda $(n=8)$, leucemia linfói de aguda $(n=6)$, doença de Hodgkin $(n=3)$ e mieloma múltiplo $(n=1)$. O congelamento foi controlado por um computador, acoplado ao sistema, às seguintes temperaturas: $-1^{\circ} \mathrm{C} / \mathrm{min}$ até

\section{NTRODUÇÃO}

A utilização das células pluripotentes (stem cell) criopreservadas, presentes na medula óssea ou no sangue periférico após sua infusão, permite a recuperação medular após a administração de altas doses de quimi oterapia ${ }^{1}$. A formação de cristais de gelo durante o processo de criopreservação é um evento importante e é a principal causa de destruição celular e retardo na recuperação medular após infusão das células descongeladas.

Os cristais de gelo intracelulares, que, muitas vezes, promovem a ruptura mecânica das estruturas celulares, são formados durante o processo de congel amento rápi do das células. No congelamento gradativo, com decréscimo gradual e constante da temperatura, a formação de gel o será primariamente extracelular, ocorrendo menor dano celular. A adição de crioprotetores penetrantes, tais $-45^{\circ} \mathrm{C}$ e depois a $-10^{\circ} \mathrm{C} / \mathrm{min}$ até $-80^{\circ} \mathrm{C}$. Após o congelamento, as células foram mantidas em freezer a $-110^{\circ} \mathrm{C}$ até 0 momento da infusão. Para obtenção das CTP, empregou-se o fator de crescimento esti mulante de granulócitos (G-CSF).

Resultados. Uma mediana de 3,16 x $10^{8}$ céls. $/ \mathrm{kg}$ (variação 0,86-24,22) de CTP e 2,03 X $10^{8}$ céls./kg (variação 0,19-12,21) de medula óssea foi congelada. A mediana para atingir granulócitos maior ou igual a $500 / \mu \mathrm{L}$ e plaquetas maior que $20.000 / \mu \mathrm{L}$ foi de 12 dias (variação 8-40) e 31 dias (variação 8-80), respectivamente. Todos os pacientes tiveram recuperação hematopoética após a infusão das células criopreservadas.

Conclusão. A criopreservação em congelador programável permite o armazenamento de células hematopoéticas e, potencialmente, pode causar menor dano celular.

UNITERMOS: Transplante de medula óssea. Congelamento. Células primitivas.

como o dimetilsulfóxido (DMSO), diminui o volume de água para formação de cristais de gelo e, conseqüentemente, o grau de desidratação da célula. Isso resulta em uma adequada criopreservação das células hematopoéticas ${ }^{1,2}$.

O objetivo do presente trabalho foi o de relatar a experiência do Serviço de Criobiologia da Disciplina de Hematologia e Hemoterapia da Universidade de São Paulo e da Fundação Pró-Sangue/ Hemocentro de São Paulo, desde a sua implantação, e os resultados obti dos com o uso associado das células-tronco periféricas (CTP) e medula óssea autógena para reconstituição hematopoética após altas doses de quimioterapia.

\section{CASUÍSTICA}

Durante o período de abril de 1993 a setembro de 1994, 23 pacientes (11 do sexo masculino e 12 do 


\begin{tabular}{|c|c|c|c|c|c|c|c|c|}
\hline Paciente & $\begin{array}{l}\text { Idade/ } \\
\text { Sexo }\end{array}$ & Diagnóstico & $\begin{array}{l}\text { Status } \\
\text { na coleta }\end{array}$ & $\begin{array}{l}\text { Status } \\
\text { no TAMO }\end{array}$ & 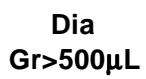 & $\begin{array}{l}\text { Dia plaquetas } \\
>20.000 / \mu \mathrm{L}\end{array}$ & $\begin{array}{c}\text { Fator de } \\
\text { crescimento }\end{array}$ & $\begin{array}{c}\text { Seguimento } \\
\text { clínico (meses) }\end{array}$ \\
\hline P.J.M. & $18 / \mathrm{M}$ & LMA & $1 \mathrm{RC}$ & $1 \mathrm{RC}$ & +8 & +34 & G-CSF & $\mathrm{RC}(+10)$ \\
\hline B.L.V.S. & $39 / F$ & LMA & $2 \mathrm{RC}$ & $2 \mathrm{RC}$ & +40 & NA & G-CSF/GM-CSF & Hemorragia GI(3) \\
\hline R.R.S. & $27 / F$ & LMA & $1 \mathrm{RC}$ & 1recidiva & +12 & NA & G-CSF & Óbito p/ falência hepática (1) \\
\hline L.M.M. & $5 / \mathrm{M}$ & LMA & $1 \mathrm{RC}$ & $1 \mathrm{RC}$ & +8 & +38 & G-CSF & $\mathrm{RC}(+5)$ \\
\hline D.K. & $26 / F$ & LMA & $3 R C$ & $3 R C$ & +22 & +80 & G-CSF & Recidiva (6) \\
\hline A.G.C. & $3 / F$ & LMA & $1 \mathrm{RC}$ & $1 \mathrm{RC}$ & +12 & +22 & G-CSF & $\mathrm{RC}(+2)$ \\
\hline M.M.N. & $14 / \mathrm{M}$ & LMA & $1 \mathrm{RC}$ & $1 \mathrm{RC}$ & +11 & +25 & G-CSF & $\mathrm{RC}(+6)$ \\
\hline K.C.R.B. & $15 / F$ & LMA & $2 \mathrm{RC}$ & $2 \mathrm{RC}$ & +17 & +80 & G-CSF & Recidiva (4) \\
\hline E.A.F. & $17 / \mathrm{M}$ & LLA & $2 R C$ & $2 \mathrm{RC}$ & +10 & NA & G-CSF & Óbito p/ aspergilose (1) \\
\hline S.R.F. & $18 / \mathrm{F}$ & LLA & $2 R C$ & $2 R C$ & +12 & NA & G-CSF & $\mathrm{RC}(+2)$ \\
\hline F.F. & $35 / \mathrm{M}$ & LLA & $2 R C$ & $2 \mathrm{RC}$ & +12 & +35 & G-CSF & Recidiva (6) \\
\hline R.G.F. & $8 / \mathrm{M}$ & LLA & $2 \mathrm{RC}$ & $2 \mathrm{RC}$ & +10 & +8 & G-CSF & Recidiva (2) \\
\hline R.G.C. & $5 / F$ & LLA & $2 R C$ & $2 \mathrm{RC}$ & +12 & +33 & GM-CSF & $\mathrm{RC}(+21)$ \\
\hline F.R. & $32 / \mathrm{M}$ & LLA & $1 \mathrm{RC}$ & $1 \mathrm{RC}$ & +8 & NA & G-CSF & Recidiva (1) \\
\hline C.G.T. & $50 / F$ & LNH & $3 R C$ & $3 R C$ & +14 & NA & G-CSF & Óbito p/ aspergilose (2) \\
\hline B.C. & $53 / F$ & LNH & $2 \mathrm{RP}$ & $2 \mathrm{RP}$ & +10 & NA & G-CSF & Óbito p/ falha múltipla de órgãos (2) \\
\hline T.G.T. & $12 / F$ & LNH & $1 \mathrm{RC}$ & $1 \mathrm{RC}$ & +9 & +20 & G-CSF & Recidiva (3) \\
\hline N.P. & $36 / F$ & LNH & $2 \mathrm{RC}$ & $2 \mathrm{RC}$ & +10 & +31 & G-CSF & $\mathrm{RC}(+11)$ \\
\hline E.S.L. & $12 / F$ & LNH & $2 R C$ & $2 \mathrm{RC}$ & +12 & +52 & G-CSF & $\mathrm{RC}(+18)$ \\
\hline A.F.B. & $29 / \mathrm{M}$ & $\mathrm{DH}$ & $2 R C$ & $2 R C$ & +12 & NA & G-CSF & Óbito p/ pneumonia intersticial (3) \\
\hline R.C.M. & $34 / \mathrm{M}$ & $\mathrm{DH}$ & $2 R P$ & $2 R P$ & +10 & +24 & G-CSF & $\mathrm{RC}(+12)$ \\
\hline J.E..O. & $34 / \mathrm{M}$ & $\mathrm{DH}$ & $2 \mathrm{RC}$ & $2 \mathrm{RC}$ & +8 & +16 & G-CSF & $\mathrm{RC}(+24)$ \\
\hline F.R.C. & $57 / \mathrm{M}$ & MM & $\mathrm{RP}$ & $\mathrm{RP}$ & +12 & +28 & G-CSF & $\mathrm{RC}(+10)$ \\
\hline
\end{tabular}

feminino), provenientes da Disciplina de HematoI ogia e Hemoterapia da Faculdade de Medicina da Universidade de São Paulo (FMUSP) e da Fundação Pró-Sangue/H emocentro de São Paulo, receberam a associação de células-tronco periféricas (CTP) e/ou medula óssea (MO) autógena para a reconstitui ção hematopoética após o regi me de condicionamento para o transplante de medula óssea.

Quanto ao diagnóstico, oito pacientes eram portadores de leucemia mielóide aguda (LMA), três com doença de Hodgkin (DH), cinco com linfoma não-Hodgkin ( $\mathrm{LNH})$, seis com leucemia linfóide aguda (LLA) e um paciente com mieloma múltiplo (MM) (tabela 1).

Quanto ao estado clínico, no momento do transplante, sete estavam em primeira remissão e 16 com doença mais avançada (segunda remissão ou doença refratária).

Dezessete pacientes receberam somente quimi oterapia como regime de condicionamento para o autotransplante e seis receberam quimi oterapia associada à radioterapia (radiação corporal total).

A col eta de medula óssea seguiu o método proposto pel o grupo de Seattle $\mathrm{e}^{3}$. Resumidamente, coletaram-se de $10-15 \mathrm{~mL} / \mathrm{kg}$ (de peso do paciente) de medula óssea por meio de múltiplas punções da região esternal e das cristas ilíacas superiores e posteriores. A seguir, a medula óssea foi filtrada por dois filtros de diâmetros diferentes $(0,33 \mathrm{~mm}$ e $0,22 \mathrm{~mm}$ ), respectivamente.

A coleta das CTP foi realizada por meio de leucoaférese, realizando-se um procedimento por dia durante três dias consecutivos, após estímulo com o G-CSF $(5 \mu \mathrm{g} / \mathrm{kg})$. As aféreses foram realizadas em equi pamento de fluxo contínuo Vivacell BT 798 (Dideco, Mirandola - I tália). E m cada coleta foram processados 10-12 litros de sangue do paciente, com fluxo de retirada de $50 \mathrm{~mL} / \mathrm{min}$ e fluxo de aspiração do buffy-coat de $3-4 \mathrm{~mL} / \mathrm{min}$. A velocidade de centrifugação foi de $180 \times \mathrm{G}$ eutilizou-se $A C D$ fórmula A como solução anti coagulante numa proporção de 1/10-1/12. O vol ume dos produtos obtidos em cada coleta foi reposto equivolumetricamente com solução de albumina a $4 \%$.

O excesso de plasma conti do no produto da col eta de CTP e da medula óssea foi removido por centrifugação em centrífuga Sorvall (3.000rpm/15min), colhendo-se, assim, a camada leucoplaquetária (buffy-coat). A contagem de células nucleadas foi feita antes e após a obtenção do buffy-coat, que foi congelado com igual volume de solução criopreservante contendo $20 \%$ de dimetilsulfóxido 


\begin{tabular}{|c|c|c|c|c|c|}
\hline Paciente & $\begin{array}{c}\text { Stem cell } \\
\text { congeladas }\end{array}$ & $\begin{array}{l}\text { Medula óssea } \\
\text { congelada }\end{array}$ & $\begin{array}{l}\text { Coleta de stem cell } \\
\text { periféricas ( } \mathrm{n}^{\circ} \text { de cél. } \times 10^{8} / \mathrm{kg} \text { ) }\end{array}$ & Medula óssea & $\begin{array}{c}\text { № de células } \\
\text { congeladas }\left(\times 10^{8} / \mathrm{kg}\right)\end{array}$ \\
\hline P.J.M. & 3 & 1 & 4,41 & 5,09 & 9,50 \\
\hline B.L.V.S. & 3 & 1 & 0,87 & 1,98 & 2,84 \\
\hline R.R.S. & 3 & 1 & 1,12 & 3,10 & 4,22 \\
\hline A.G.C. & --- & 1 & -- & 6,04 & 6,04 \\
\hline M.M.N. & 3 & 1 & 1,36 & 5,18 & 6,54 \\
\hline K.C.R.B. & 3 & 1 & 2,98 & 2,26 & 5,24 \\
\hline E.A.F. & 3 & 1 & 3,16 & 0,19 & 3,34 \\
\hline S.R.F. & 3 & 1 & 1,65 & 0,24 & 1,89 \\
\hline F.F. & 3 & 1 & 7,03 & 1,57 & 8,60 \\
\hline B.C. & 2 & 1 & 3,17 & 2,24 & 5,41 \\
\hline T.G.T. & 3 & 1 & 3,01 & 1,79 & 4,80 \\
\hline N.P. & 3 & 1 & 2,54 & 3,34 & 5,88 \\
\hline E.S.L. & 3 & 1 & 2,65 & 1,98 & 4,63 \\
\hline A.F.B. & 3 & 1 & 3,42 & 12,21 & 5,12 \\
\hline R.C.M. & 2 & 1 & 12,03 & 2,41 & 16,85 \\
\hline J.E..O. & 3 & 1 & 7,77 & 1,50 & 9,27 \\
\hline F.R.C. & 3 & 1 & 24,22 & 2,52 & 26,74 \\
\hline
\end{tabular}

(DMSO, Cryoserv, Research Industries Corporation, Utah), 40\% de meio de cultura (TC199, Instituto Adolfo Lutz, São Paulo) e $40 \%$ de plasma autógeno. As células do buffy-coat foram congeladas em uma câmara de congelamento programável (CRYOMED, mod.1010, Ohio). A câmara é alimentada por cilindro de nitrogênio líquido VGL (White Martins, São Paulo, 116 litros de capacidade). A taxa de congelamento foi à razão de $-1^{\circ} \mathrm{C} / \mathrm{min}$ da temperatura ambiente até $-45^{\circ} \mathrm{C}$ e, a seguir, a $-10^{\circ} \mathrm{C} / \mathrm{min}$ até $-80^{\circ} \mathrm{C}$, antes de serem transferidos para um freezer mecânico a $-110^{\circ} \mathrm{C}$ (F orma Científica, mod 8380, Ohio) [ver gráfico na pág. seguinte].

Antes da reinfusão, as células foram rapidamente descongeladas ( 3 a 5 minutos), em banhomaria a $37^{\circ} \mathrm{C}$, ao lado do leito do paciente. Foi adicionado anticoagulante (ACD) correspondente a $20 \%$ do volume total de cada bolsa, para evitar a formação de coágulos celulares. Os critérios de recuperação medular após o autotransplante foram: granulócitos superiores ou igual a $500 / \mu \mathrm{L}$ por dois dias consecutivos e plaquetas superiores a 20.000/ $\mu \mathrm{L}$ por uma semana sem transfusão.

Todos os pacientes receberam fator de crescimento (G-CSF) a partir do dia +1 do TMO até a recuperação hematopoética. U ma paciente (RGC) recebeu GM-CSF e outro (RRS), G-CSF e GM-CSF, alternadamente, como fatores estimulantes, por problemas de fornecimento.

\section{RESULTADOS}

Oitenta e seis congelamentos foram realizados naquele período. O número de coletas, tanto das CTP como de medula óssea, está relacionado na tabel a 2. A mediana de col etas de CTP e de medula óssea por paciente foi de 3 e 1, respectivamente. Todos os congel amentos foram registrados graficamente por meio de uma curva de congelamento (gráfico). A curva é composta de três fases (A: fase inicial; B: fase crítica e C: fase final).

Os pacientes receberam uma mediana de 5,31 x $10^{8}$ cels./kg (variação 1,68-26,74) de CTP associada a medula óssea autógena. Dois pacientes (RGC e $A G C$ ) receberam apenas medula óssea, pois não foi possível coletar CTP devido ao peso dos pacientes.

A mediana do tempo de recuperação medular foi de 12 dias (variação 8-40) para os granulócitos e de 31 dias (variação 8-80) para as plaquetas.

Dos 23 pacientes admitidos no Programa de Transplante de Medula Óssea, 11 permanecem vivos e livres da doença, com mediana de 11 meses (variação 2-24) de seguimento clínico. Um paciente $(R G F)$ teve recidiva precoce $($ dia +86$)$ e morreu 


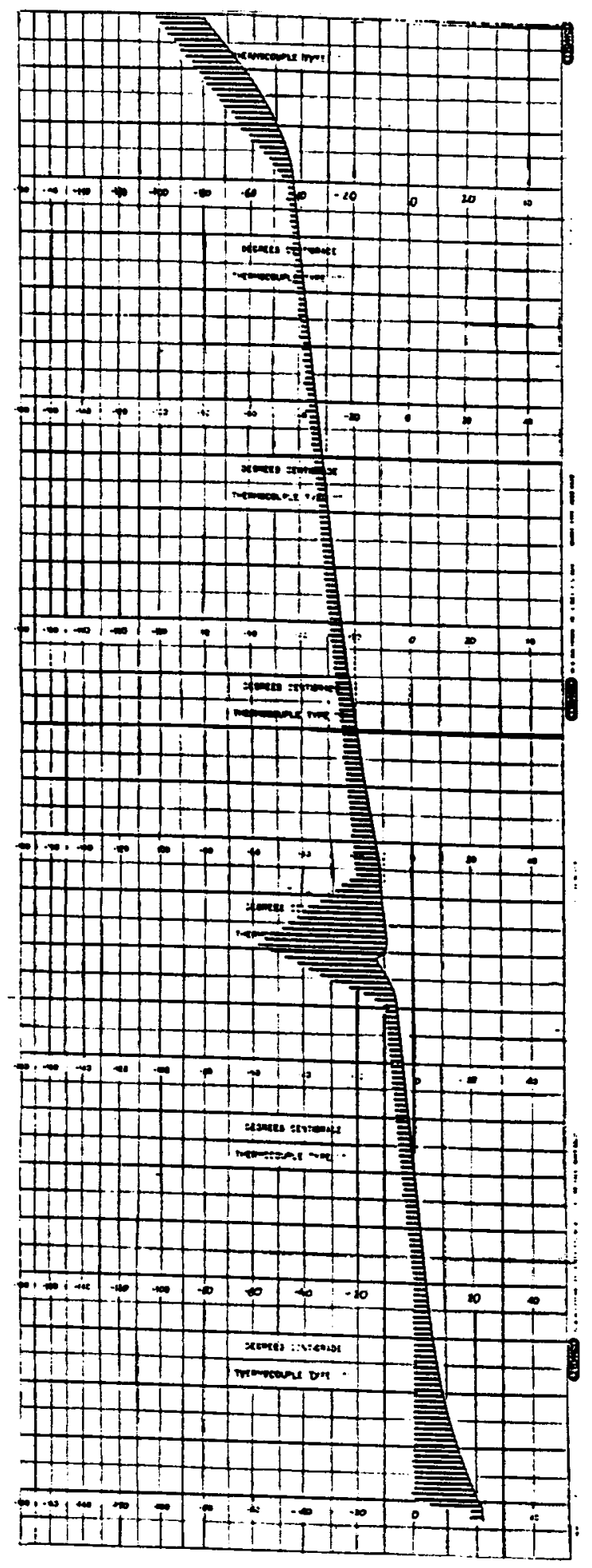

Gráfico - Curva de congelamento: A) fase inicial: decréscimo da temperatura à razão de $-1^{\circ} \mathrm{C} / \mathrm{min}$ até $-45^{\circ} \mathrm{C}$; B) fase crítica: liberação do cal or de fusão pelas células; C) fase final: decrésci mo da temperatura à razão de $-10^{\circ} \mathrm{C} / \mathrm{min}$ até $-80^{\circ} \mathrm{C}$.
Tabela 3 - Causas de óbito

\section{Recidiva}

Hemorragia gastrointestinal

Toxicidade hepática (Insuficiência hepática)

Infecção

Pneumonia intersticial

após três meses. Os demais paci entes morreram de outras causas (tabela 3).

\section{DISCUSSÃO}

O tratamento com altas doses de quimioterapia, seguido da infusão de células precursoras hematopoéticas, está sendo incorporado ao contexto terapêutico com finalidades curativas para uma série de neoplasias ${ }^{4}$. A importância das células pluripotentes após a quimioterapia mieloablativa faz-se notar pela reconstituição hematopoética e, também, pela redução das intercorrências como neutropenia, infecções oportunistas e dias de hospitalização, entre outros, os quais podem ser reduzidos ainda mais se empregados fatores de crescimento, associadamente ${ }^{5}$.

O transplante autólogo ou autoplástico de medula óssea (TAMO) passa a ter papel importante quando se visa administrar altas doses de quimioterapia. A coleta das células precursoras para a realização do TAMO pode se dar por via direta das células mediante múltiplas punções das cristas ilíacas ou por meio de uma técnica mais recente, a das células pluripotentes periféricas ${ }^{6}$. Em nosso trabalho, utilizamos a associação da medula óssea autóloga e das CTP. Disso resultou um número superior a 5,0x $10^{8}$ cels. $/ \mathrm{kg}$, garantindo recuperação medular para todos os pacientes.

Recentemente, vários procedimentos têm sido empregados para aumentar a coleta de células progenitoras $6,7,9$. Richman et al. observaram aumento do número de CFU-GM (colony forming unit granulocyte-macrophage), presentes no sangue periférico de pacientes que receberam quimioterapia não-mi el oablativa coinci dente com a recuperação dos leucócitos ${ }^{8}$. O mesmo fenômeno foi observado durante o tratamento de indução na leucemia mielóide aguda e, após quimioterapia, para linfoma não-Hodgkin. Abrams et al. demonstraram um efeito semel hante em cães, que receberam cicl ofosfamida ${ }^{10}$. E sses autores notaram que a coleta de células, após estímulo com o quimioterápico, resultou em número 12 vezes mai or do que o obtido em animais-controle, sem estímulo. 
Os fatores de crescimento também têm sido empregados para mel horar o rendimento da col eta das células. Socinski et al. relataram aumento médio de 15 vezes no número de CFU-GM no sangue periférico, após a infusão de GM-CSF (granulocyte-macrophage colony stimulating factor), com doses escal onadas de $4-64 \mu \mathrm{g} / \mathrm{kg}$, em pacientes com tumores sólidos que não receberam quimioterapia ${ }^{11}$. Estudo semelhante, realizado por Gianni et al., resul tou em aumento de CF U-GM circulante em 25 vezes com ciclofosfamida sozinha, e 1001.000 vezes com cicl ofosfamida mais GM-CSF ${ }^{12}$.

Altas doses de quimioterapia, tais como com ci cl ofosfamida e VP-16, seguidas de G-CSF, talvez tornem desnecessárias múltiplas coletas de células e resultem em um produto com menor quantidade de células tumorais. Esse esquema também traz a vantagem de produzir uma citorredução inicial antes das altas doses de quimi oterapia para o TAMO e, com isso, consegue-se avaliar a quimiossensibilidade do tumor.

Desses trabalhos resultou que a melhor técnica de coleta das células precursoras hematopoéticas (CD34+) seria a combinação de quimioterapia seguida de fator de crescimento. Embora existam publicações recomendando um número mínimo de células $\left(30 \times 10^{4}\right.$ CF U-GM/kg e 2,0x106céls. CD34+/ kg) para a recuperação hematopoética precoce, não foi possível, até o momento, estabelecer um número ideal de células a serem coletadas ${ }^{13}$. Parece ser importante que cada instituição defina, em função do protocol o de mobi lização das células, qual será o número destas a serem col etadas ${ }^{12}$. Mais recentemente, diversos autores têm realizado a determinação de células CD34 positivas no material de CTP ${ }^{14}$. I sto porque todas as células que crescem em colônias e algumas células mononucleares expressam o antígeno CD34. Algumas insti tuições ${ }^{9,14}$ têm relatado o número míni mo de células CD34+necessárias para obter uma recuperação medular precoce. Em nosso trabalho, os pacientes tiveram a medula óssea ou CTP coletadas após a quimi oterapia de resgate ou sob estímulo com fator de crescimento. A mai oria dos pacientes recebeu G-CSF após o TAMO com o intuito de acelerar a recuperação hematopoética. U ma mediana de 12 dias de recuperação dos granulócitos, após o autotransplante, foi observada no presente trabal ho, estando de acordo com outros relatos da literatura ${ }^{9}$. A recuperação hematopoética é um bom índice para avaliar a criopreservação das células pluripotentes hematopoéticas ${ }^{7}$. O uso rotineiro de CTP tem reduzido o tempo de recuperação da hematopoese. Korbling et al., estudando pacientes com linfoma de Burkitt em remissão completa que receberam CTP após radioterapia corporal total e cicl ofosfamida, observaram recuperação precoce de neutrófilos e plaquetas (dias 9 e 10 pós-transplante, respectivamente) $)^{15}$. Não houve nenhum caso de falência medular em nossa casuística. U ma paciente (ESL) teve, durante a recuperação hematopoética, pneumonia inter sticial de causa não identificada, sendo necessário o uso do ganciclovir; neste caso, a paciente teve recuperação medular tardia, possivelmente por mielotoxicidade do ganciclovir. Em outra paciente (BLVS), a recuperação medular ocorreu no dia +40 após transplante de medula óssea. Tratava-se de paciente com LMA secundária à adenocarcinoma de mama, intensamente tratada com quimioterapia, motivo pelo qual deveria ter poucas células CD34+ na medula óssea.

O uso de CTP tem facilitado uma recuperação medular precoce, e isso se traduz por menor morbidade, menor mortalidade e, principalmente, menor custo, permitindo ampliar seu uso terapêutico ${ }^{16,17}$.

\section{SUMMARY}

\section{Cryopreservation of bone marrow and peripheral blood stem cells using a controlled rate freezing system. Experience on 86 procedures}

The cryopreservation of hematopoi etic stem cells can be used for rescuing the hematopoiesis after high dose chemotherapy.

Purpose. The ice cristal formation during the freezing procedure is the key point that can be harmful to the cells. The cryopreservation of he matopoi etic stem cells in a controlled-rate freezer could decrease the cell damage.

Methods. Twenty-three patients with a median age of 26 years (range 03-57) had bone marrow and/ or peripheral blood stem cells harvested from March 1993 through October 1994, ending up to 86 freezing procedures.

The patient's diagnoses are as follows: NonHodgkin's Lymphoma $(n=5)$; Acute Myelogenous Leukemia $(n=8)$; Acute Lymphocytic Leukemia $(n=6)$; Hodgkin's di sease $(n=3)$; Multi ple Myel oma $(n=1)$. The cells were frozen away in a controlledratefreezer chamber at the fol owing rate: $-1^{\circ} \mathrm{C} / \mathrm{min}$ from room temperature to $-45^{\circ} \mathrm{C}$ and then, at $10^{\circ} \mathrm{C} / \mathrm{min}$ down to $-80^{\circ} \mathrm{C}$. After freezing, the cells were kept into mechanical freezers until the marrow infusion. To mobilize PBSC (peripheral blood stem cells), G-CSF (granul ocyte col ony stimulating factor) was given.

Results. A median of $3.16 \times 10^{8}$ cells/ kg (range $0.86-24.22)$ of PBSC and $2.03 \times 10^{8}$ cells/ kg (0.19- 
12.21) of bone marrow cells were frozen. The me dian time to reach granulocytes greater than 500/ $\mu \mathrm{L}$ and platelets greater than $20,000 / \mu \mathrm{L}$ was 12 days (range 8-40) and 31 days (range 8-80), respectively. All patients had marrow engraftment after infusion of hematopoi etic stem cells.

CONCLUSION. The cryopreservation procedure using a controlled-rate freezer can store hematopoietic stem cel Is and potentially, causel ess damageto the cells. [Rev Ass Med Brasil 1997; 43(2): 93-8.]

KEY WORDS: Bone marrow transplantation. Cryopreservation. Stem cell.

\section{REFERÊNCIAS BIBLIOGRÁFICAS}

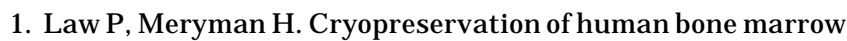
grafts. In Gee A: Bone marrow processing and purging. A practical guide. $1^{\text {th }}$ ed, Flórida, CRCPress, 1991; 332-40.

2. Rowley SD. Techniques of bone marrow and stem cell cryopreservation and storage. In Sacher RA, AuBuchon J P (eds): Marrow transplantation: practical and technical aspects of stem cell reconstitution. $1^{\text {th }}$ ed. Maryland, American Association of Blood Banks, 1992; 105-27.

3. Stewart P, Buckner CD, Bensinger $W$ et al. Autologous bone marrow transplantation in patients with acute nonlymphocytic leukemia in first remission. Exp Hematol 1985; 13: 267-72.

4. Cavins J A, Scheer SC, Thomas ED, Ferrebee J W. The recovery of lethally irradiated dogs given infusions of autologous leukocytes preserved at $-80^{\circ} \mathrm{C}$. Blood 1964; 23 : 38-43.

5. Messner HA, McCulloch EA. Mechanisms of human hematopoiesis. In Forman SJ , Blume KG, Thomas ED (eds): Bone marrow transplantation. $1^{\text {th }}$ ed, Boston, Blackwell Scientific Publications, 1993; 41-52.

6. Lasky LC, Hurd DD, Smith J A, Haake R. Peripheral blood stem cell collection and use in Hodgkin's disease. Transfusion 1989; 29: 323-7.

7. Shpall EJ, J ones RB. Mobilization and collection of peripheral blood progenitor cells for support of high-dose cancer therapy. In Forman SJ , Blume KG, Thomas ED (eds): Bone marrow transplantation. $1^{\text {th }}$ ed, Boston, Blackwell Scientific Publications, 1993; 913-8.

8. Richman CM, Chess L, Yankee RA. Purification and characterization of granulocytic progenitor cells (CFU-C) from human peripheral blood using immunologic surface markers. Blood 1978; 51: 1-8.

9. To LB, Dyson PG, J uttner CA. Cell-dose effect in circulating stem cell autografting. Lancet 1986; 2: 404-5.

10. Abrams RA, Galubiger D, Appelbaum FR, Deisseroth AB. Result of attemptes hematopoi etic reconstitution using isologous peripheral blood mononucl ear cells. A case report. Blood 1980; 56: 516-20.

11. Socinski MA, Elias A, Schnipper L. Granulocyte-macrophage col ony stimulating factor expands the circulating hemopoi etic progenitor cell compartment in man. Lancet 1988; 1: 1.194-8.

12. Gianni AM, Bregni M, Siena. Recombinant human granulocyte-macrophage col ony stimulating factor reduces hematologic toxicity and widens clinical applicability of highdose cyclophosphamide treatment in breast cancer and nonHodgkin's lymphoma. J Clin Oncol 1990; 8: 768-78.

13. Cirenza E. Peripheral blood progenitor cells: mobilization and transplantation. In Smich DM, Sacher RA (eds): Peripheral blood stem cells. Bethesda, American Association of Blood Banks, 1993; 45-63.

14. Siena S, Bregni M, Brando B et al. Circulation of CD34+ hematopoietic stem cells in the peripheral blood of high-dose cyclophosphamide - treated patients: enhancement colonystimulating factor. Blood 1989; 74(6): 1.905-14.

15. Korbling M, Dorken B, Ho AD et al. Autologous transplantation of blood-derived haemopoietic stem cells after myeloablative therapy in a patient with Burkitt's Iymphoma. Blood 1986; 67: 529-32.

16. J ones HM, J ones SA, Watts MJ et al. Development of simplifed single-apheresis approach for peripheral blood progenitor-cell transplantation in previously treated patients with Iymphoma. J Clin Oncol 1994; 12(8): 1.693-702.

17. Peters W, Rosner $G$, Ross $M$ et al. Comparative effects of granulocyte-macrophage colony-stimulating factor (GM-CSF) and granulocyte-stimulating factor (G-CSF) on priming peripheral blood progenitor cells for use with autologous bone marrow after high-dose chemotherapy. Blood 1993; 81(7): 1.709-19. 